\title{
Viable Alternatives to in vivo Tests for Evaluating the Toxicity of Engineered Carbon Nanotubes
}

\author{
Soonjo Kwon ${ }^{\dagger}$ and Soo-mi Eo* \\ Department of Biological Engineering, Utah State University, Logan, UT 84322, USA \\ *Seoul Metropolitan Government Research Institute of Health and Environment, Seoul, Korea
}

\begin{abstract}
Carbon nanotubes (CNTs) stand at the frontier of nanotechnology and are destined to stimulate the next industrial revolution. Rapid increase in their production and use in the technology industry have led to concerns over the effects of CNT on human health and the environment. The prominent use of CNTs in biomedical applications also increases the possibility of human exposure, while properties such as their high aspect ratio (fiber-like shape) and large surface area raise safety concerns for human health if exposure does occur. It is crucial to develop viable alternatives to in vivo tests in order to evaluate the toxicity of engineered CNTs and develop validated experimental models capable of identifying CNTs' toxic effects and predicting their level of toxicity in the human respiratory system. Human lung epithelial cells serve as a barrier at the interface between the surrounding air and lung tissues in response to exogenous particles such as air-pollutants, including CNTs. Monolayer culture of the key individual cell types has provided abundant fundamental information on the response of these cells to external perturbations. However, such systems are limited by the absence of cell-cell interactions and their dynamic nature, which are both present in vivo. In this review, we suggested two viable alternatives to in vivo tests to evaluate the health risk of human exposure to CNTs.
\end{abstract}

Key words: CNT toxicity, 3D co-culture, Dynamic cell culture, CNT diffusion

\section{Introduction}

Recently, there has been an increasing demand for products that utilize carbon nanotube (CNT) technology requiring large scale production of the nanotubes. In order to meet the growing demand of consumers, manufacturers are attempting to refine their fabrication process. The need for this rectification lies not only in the need to produce CNTs on a mass scale but also to protect their employees from the potential harmful effects of CNTs. There are two routes through which human could be exposed to CNTs: accidental exposure, essentially to an aerosol in the context of CNT production and handling; and exposure as a result of CNT use for biomedical purposes. Unfortunately, research into understanding and preventing the risk of newly developed materials, such as CNTs, has a low priority in the competitive world of research funding and technology development. Accordingly, few studies have been done regarding the potential toxic levels of the CNTs when inhaled or skin-contacted. The size of the CNTs makes them more readily become airborne and can therefore create the risk of being inhaled by a worker. There are many uncertainties as to whether the unique properties of engineered nanomaterials affect occupational health risks. These uncertainties arise because of gaps in knowledge about the factors that are essential for predicting health risks - factors such as routes of exposure, translocation of materials once they enter the body, and interaction of the materials with the body's biological systems. The potential health risk following exposure to a substance is generally associated with the magnitude and duration

Corresponding author: Department of Biological Engineering, Utah State University, 4105 Old Main Hill, Logan, UT 84322-4105, USA, Tel: +1-435-797-7481, Fax: +1-435-797-1248, E-mail: soonjo.kwon@usu.edu Received: 10 January 2012, Revised: 10 February 2012, Accepted: 17 February 2012 
of the exposure, ${ }^{1)}$ the persistence of the material in the body, the inherent toxicity of the material, and the susceptibility or health status of the person exposed. More data are needed on the health risks associated with exposure to engineered nanomaterials such as CNTs.

Properties such as high aspect ratio (fiber-like shape) and large surface area of CNTs may raise safety concerns for human health if exposure does occur. Recent studies indicate CNTs have produced toxic effects on biological systems. ${ }^{2-6)}$ Intensive studies on the toxicity of CNTs have shown that exposure to CNTs results in pulmonary inflammation. ${ }^{7-13)}$ The inflammatory lung reactions (alveolitis) are a source of genetic lesions, which could eventually lead to the development of lung cancer. ${ }^{7)}$ In vivo studies performed using guinea pigs and rats showed the appearance of multifocal granulomas, resulting in inflammatory reactions of the terminal and respiratory bronchioles. Mild fibrosis in the alveolar septa was also observed. ${ }^{4)}$ Ken Donaldson and his colleagues described three properties of CNTs associated with pathogenicity in particles. They are (1) nanoparticles showing more toxicity than larger sized particles, (2) fiber-shaped particles behaving like asbestos and other pathogenic fibers that have toxicity associated with their needle-like shape, and (3) biologically persistent. They also pointed out that CNTs are possibly one of the least biodegradable man-made materials ever devised. ${ }^{14)}$ Also concerns over the increased emissions of CNTs into the environmental compartments (air, water, and soil) mainly due to improper disposal of CNTs were raised. ${ }^{4)}$

Lung epithelial cells act as a barrier at the interface between surrounding air and lung tissues in respond to exogenous particles such as air-pollutants including CNTs. Monolayer culture of the key individual cell types has provided abundant fundamental information on the response of these cells (e.g., epithelium, fibroblast, and smooth muscle) to external perturbations. These systems are limited by the absence of cellcell interactions and dynamic nature, which are present in vivo. In this review, two viable alternatives to in vivo tests was suggested to evaluate the toxicity of engineered CNTs and to develop validated experimental models capable of identifying the variation effects of CNTs and predicting the level of cytotoxity of CNTs in the human respiratory system.

\section{Alternative methods for health risk assessment of human exposure to nanoparticles}

\section{Static Model: 3-dimensional tissue-engineered lung}

More recently, a contracting fibroblast-embedded collagen gel has provided a model to simulate human airway. ${ }^{15-21)}$ Fibroblasts naturally contract the extracellular matrix (ECM) to close a wound, and, when placed in a collagen gel, respond in a similar fashion and contract the gel. Another in vitro model of airway involves culturing epithelial cells as monolayer on a membrane and fibroblasts as a monolayer a fixed distance away separated by culture medium. ${ }^{22,23)}$ This model is attractive as it isolates soluble mediators that participate in epithelialfibroblast communication, but lacks the normal ECM and anatomical dimensions. The model of the airway presented in this review has several important features: (1) It maintains the normal anatomical arrangement (orientation and dimensions) of epithelial and fibroblast cells. (2) The fibroblast is embedded in collagen I, yet remains anchored. (3) A thin $(10-\mu \mathrm{m})$ porous polyester membrane separates the epithelial and fibroblast cell, allowing not only communication between the epithelium and fibroblast, but also clean access to investigate cell-specific protein expression, following exposure to external perturbation.

Several different tissue engineered models of the respiratory mucosa which are all comprised of an epithelial cell monolayer co-cultured with a fibroblastimbedded collagen gel have been utilized. The coculture technique in this review offers several distinct advantages over earlier models. The airway epithelial cells are cultured as a monolayer over a thin $(10 \mu \mathrm{m})$ porous polyester membrane. A thin lung fibroblastembedded collagen layer is attached to the opposing side of membrane. In this fashion, the epithelial cells and fibroblast cells maintain the normal anatomical arrangement, but the polyester membrane allows easy separation of the cell types for cell-specific gene expression and proteomics analysis. In addition, the air-liquid interface is more easily controlled, and the collagen gel is anchored thus maintaining tension in the matrix that more closely resembles the in situ condition (Fig. 1). Fibroblast-embedded Collagen I gels are prepared using rat tail tendon collagen (RTTC; Collaborative, Bedford, MA, USA). Normal 


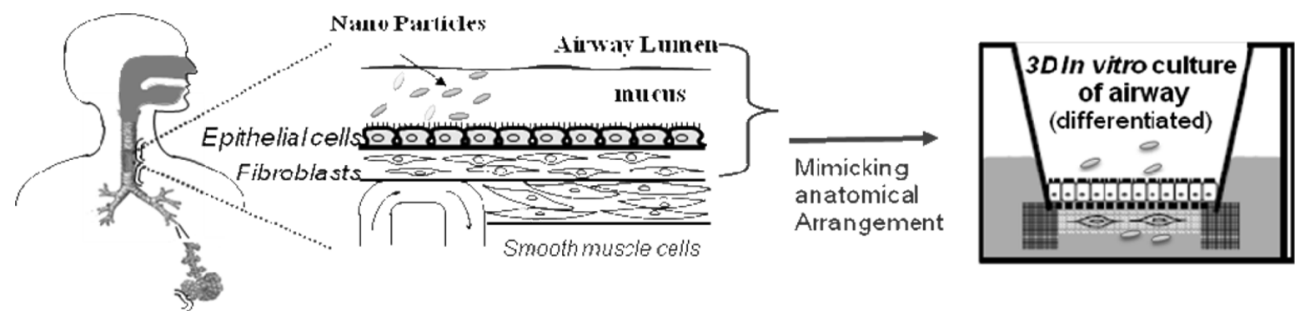

Fig. 1. Preparation of tissue engineered bronchial mucosa follows three major steps and three weeks in culture.

human lung fibroblasts (NHLF) are harvested upon reaching $75-80 \%$ confluence, and added (seeding density of $5 \times 10^{4}$ fibroblasts $/ \mathrm{m} l$ of final volume) to an iced mixture of collagen (final concentration $2.0 \mathrm{mg} / \mathrm{ml})$, 5X concentrated DMEM, and 10X reconstitution buffer comprised of $\mathrm{NaHCO}_{3}$, HEPES buffer (Gibco, Grand Island, NY, USA) and $\mathrm{NaOH}$. Aliquots of the mixture are pipetted onto the underside of a $1 \mathrm{~cm}^{2}$ Transwell (Costar, Cambridge, MA, USA) polyester membrane $(0.4 \mu \mathrm{m}$ pore). The outer rim of the membrane is fitted with a highly porous polyethylene ring. The liquid gel then seeps into the porous ring at the edge and upon "gelling" is able to keep the fibroblast-embedded gel from contracting. The collagen mixture is then allowed to "gel" (non-covalent cross-link) at $37^{\circ} \mathrm{C}$ in $5 \% \mathrm{CO}_{2}$ for 10-15 minutes. Harvested primary human bronchial epithelial (HBE) cells (passage 2-3) are then seeded $\left(1.5 \times 10^{5}\right.$ cells $\left./ \mathrm{cm}^{2}\right)$ directly on top of the polyester membrane. The entire tissue is submerged in media for 5 days and the epithelium is allowed to attach and become confluent. For the first 48 hours, the media is basal epithelial growth medium (BEGM, Clonetics, USA) and a low retinoic acid concentration. For days 3-5 (and days 6-21), the media is a 50:25:25 mixture of BEGM:DMEM:Hams F12 with a high retinoic acid concentration. At day 6 , an airliquid interface is established (media maintains a high retinoic acid concentration) and the epithelium is allowed to differentiate for approximately two weeks at which time it is ready for experimentation.

Human bronchial epithelial cells are grown at the interface of air and liquid. Culture media is provided from the bottom through the porous membrane. Transepithelial electrical resistance (TER) of human bronchial epithelial cell with fibroblasts-embedded collagen layers cultured in Transwell ${ }^{\mathrm{TM}}$ can be monitored using a portable Voltohmmeter (Millipore, Bedford, MA, USA) attached to a dual "chopstick"

http://www.kseh.org/ or transcellular resistance measurement chamber (Millipore, Bedford, MA, USA). Each of the two electrode systems contains $\mathrm{Ag} / \mathrm{AgCl}$ electrode for measuring voltage and a concentric spiral of silver wire for passing current across the epithelium. Electric current can then be passed across the epithelium to measure TER $\left(\mathrm{ohms} . \mathrm{cm}^{2}\right)$. It is perceived that TER values higher than the background fluid resistance indicate a confluent airway epithelium with tight junctions. TER is monitored to identify the perturbation in the normal physiology and permeability of human bronchial epithelial cells. ${ }^{24)}$ In the recent study, different concentrations of CNTs were exposed to the co-culture layers for 6 hours. The TER of the controls $(5 \%$ and $20 \%$ of Triton X100 and $0 \%$ of CNTs) were stable around 500 ohms. $\mathrm{cm}^{2}$ (resistance of epithelial-free tissue was subtracted) for 48 hours. $10-20 \%$ of CNTs rapidly compromised the barrier function of the epithelium

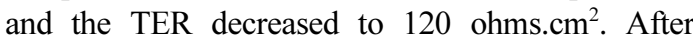
removing CNTs, the TER completely recovered to the control level. ${ }^{35)}$

2. Dynamic Model: Integration of 3D engineered tissues into a diffusion chambers

The mass transfer rate of CNTs across the cellular monolayers and the co-culture will be measured using the diffusion chamber depicted in Fig. 2. The monolayer or co-culture will be grown on a Snapwell ${ }^{\mathrm{TM}}$. The Snapwell ${ }^{\mathrm{TM}}$ will be positioned in the diffusion chamber, and the lower compartment perfused with media. The CNTs can diffuse through the cultured cells. The intracellular kinetics would be difficult to discern, but we can measure the net flux CNTs across the cellular layer. The mass transfer coefficient, $\kappa\left(\mathrm{cm} \cdot \mathrm{s}^{-1}\right)$, can be defined in a fashion which describes the net flux of CNTs across the cellular barrier, or the net flux of CNTs into the lower compartment, $\mathrm{J}_{\mathrm{L}}\left(\mathrm{mg} \cdot \mathrm{s}^{-1} \cdot \mathrm{cm}^{-2}\right)$, based on a concen- 
tration difference across the compartments:

$$
J_{L}=\kappa\left(C_{U, C N T}-C_{L, C N T}\right)
$$

where $\mathrm{C}_{\mathrm{L}, \mathrm{CNT}}$ and $\mathrm{C}_{\mathrm{U}, \mathrm{CNT}}$ are the concentrations of CNTs in the lower and upper compartment, respectively. In this fashion, $\kappa$ is a single parameter that combines the physical characteristics of the tissue such as diffusion, solubility, kinetics, and membrane thickness into a single parameter. By following the concentrations of CNTs in the upper and lower compartments with time, one can estimate the mass transfer coefficient of CNTs across the cellular layer.

The diffusion chamber can be modeled as a membrane that separates an upper and lower chamber. Using the definition of $\kappa$ provided in Equation (1), then combining an unsteady mass balance on each compartment with a central difference approximation for the accumulation rate of mass within each compartment, the following expression for $\kappa$ is easily derived:

$$
\kappa(t)=\frac{V_{U}\left[C_{U, C N T}(t-\Delta t)-C_{U, C N T}(t+\Delta t)\right]}{2 A_{m}(\Delta t)\left[C_{U, C N T}(t)-C_{L, C N T}(t)\right]}
$$

where $V_{U}$ is the volume of the upper compartment, and $A_{m}$ is the surface area of the membrane.

A distinct advantage of the in vitro system is the isolation of mass transfer resistances through individual cellular layers in an effort to isolate more clearly the transport mechanisms. Hence, the mass transfer coefficient and net fluxes of each CNT can be measured through: 1) each individual cell monolayer, and 2) co-culture of epithelial cells and fibroblasts. In addition, the initial concentration of CNTs in the media of the upper compartment can be varied to determine the effects of CNT concentration and CNT size on the kinetics and rate of mass transfer. The results will allow one to determine if the individual cells, or their interaction with each other, affect the overall mass transfer of CNTs. In addition, the mass transfer coefficient (a conductance) across the cells in co-culture (e.g., $\kappa_{\text {ef }}$, the coefficient across the epithelium and fibroblast layer) will not be equal to the sum of the coefficients from the individual monolayers $\left(\kappa_{\mathrm{e}}\right.$ and $\left.\kappa_{\mathrm{f}}\right)$ due to interaction between the cells, which affects the intracellular chemistry.

Although TER data (especially, the decrease in TER at high concentration of CNTs) indirectly tell that CNTs can possibly penetrate through the cell layers, translocation through the individual cell, accumulation, and accumulation after translocation of CNTs need to be observed microscopically with fluorescence labeling.

\section{Dynamic Model: Integration of 3D engineered} tissues into cyclic mechanical strain device

Dynamic cell growth condition serves as more realistic in vitro model (viable alternative to in vivo model). A dynamic cell growth environment was established to mimic the dynamic changes in the amount of circumferential and longitudinal expansion and contraction occurred during normal breathing

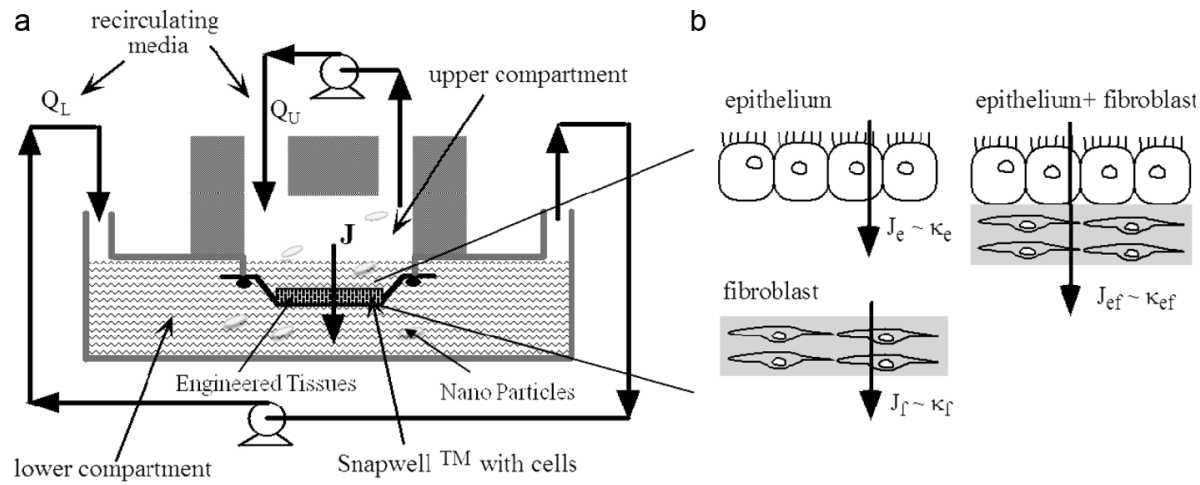

Fig. 2. Translocation of CNTs across cell layer(s). (a) Schematic of diffusion chamber for measurement of mass transfer rates of CNTs through the cellular tissue. $\mathrm{Q}_{\mathrm{L}}$ and $\mathrm{Q}_{\mathrm{U}}$ are volumetric flow rates to the lower and upper chambers, respectively. (b) Schematic of the mass transfer coefficients that can be measured for a different type of CNT simultaneously in Specific Aims 3 and 4. The flux, J, is proportional $(\sim)$ to the mass transfer coefficient, $\kappa$ (equations (1) and (2)). Subscripts: e, epithelium; f, fibroblast. 


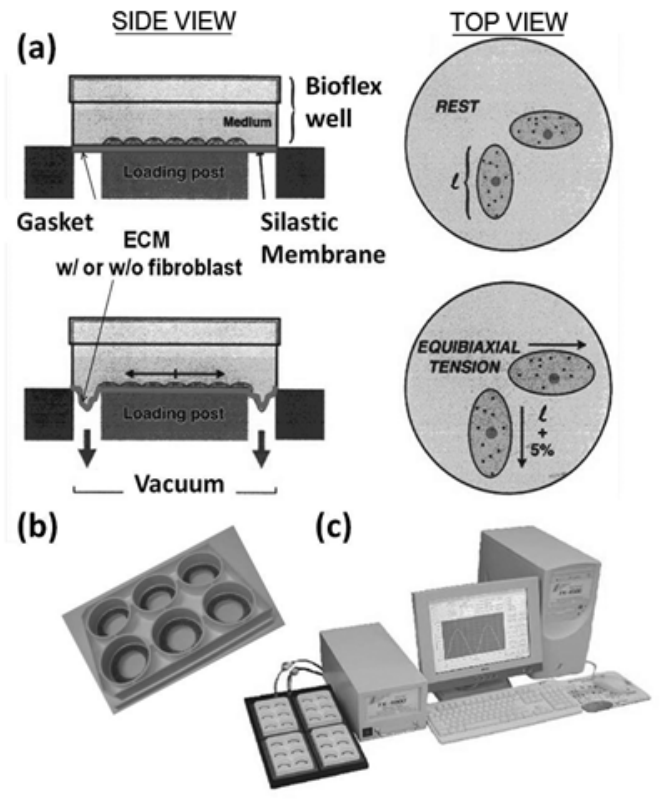

Fig. 3. The apparatus to apply tensional stress. (a) Schematic of the constant or cyclic tensional stress driven by a vacuum. (b) Circular Tissue Train $^{\mathrm{TM}}$ Culture System for the mechanical loading of cells in a 3D matrix or for culturing cells in a mechanically active environment. (c) A computer-regulated bioreactor that uses vacuum pressure to apply cyclic or static strain to cells cultured on flexible-bottomed culture plates.

movement in the lung (Fig. 3). Dynamic cell growth environment may provide a realistic condition for facilitating interaction between CNTs and cells, CNTs' uptake, and hence their effects on cells similar to in vivo. ${ }^{25-27)}$ CNT-induced effects may depend on the shape, density, size, and breathing pattern. ${ }^{12,28-31)}$ Flexcell Tension Plus system can be used to implement $5 \%$ cyclic equibiaxial elongation, which is equivalent to $45 \%$ of total lung capacity and the amount of stretching experienced during normal breathing condition. ${ }^{32,33)}$ Moreover, the equibiaxial elongation frequency is set as $0.2 \mathrm{~Hz}$, which is corresponding to the normal human breathing rate. Patel and coworkers recently showed the differences in cellular responses (cell proliferation, cellular inflammation, reactive oxygen species (ROS), and glutathione (GSH)) to air pollutants including CNTs between dynamic and static cell growth environments, and demonstrated that implementing dynamic cell growth conditions was more close approximation of in vivo conditions. ${ }^{1)}$ This study provided one of the alternative ways to evaluate CNT-induced effects on human respiratory systems and a detailed insight for the development of a viable alternative to existing static in vitro or in vivo tests.

\section{Summary}

Using the co-culture system, it will be possible to address the following important questions: (1) How do two different types of lung cells interact with each other to respond to CNT exposure? (2) What are the cellular and molecular mechanisms of cytotoxic response and interaction in the human respiratory system? and (3) How will different size and structure of CNTs be translocated and accumulated to alter the mechanisms of cellular response and specific gene expression pattern?

The dynamic cell growth system provides important changes in cellular responses that were not found in the static cell growth system and similar to animal studies. The dynamic cell growth system can be considered as viable alternative to in vivo test system in combination with existing in vitro static cell growth systems to evaluate the cellular responses on the respiratory system following exposure of different types of CNTs.

To identify the mechanisms of CNT-induced inflammatory response under different exposure conditions, multiple inflammatory markers and various candidate biological markers (cellular component, macromolecules, other metabolic parameters, and cellular function) need to be monitored. In addition, comparative studies with normal cell lines and novel experimental set-ups for a multiplexed screening of biological markers ${ }^{34)}$ will be required to unravel the uncertainty of CNT-induced inflammatory responses. Continued in vivo and in vitro toxicological research is needed to identify potential health endpoints related to occupational exposure to engineered nanoparticles such as CNTs. Epidemiological studies of exposed workers will be needed to establish associations between exposures to engineered nanoparticles and adverse health effects and to assess other potential exposure-response relationships. 


\section{References}

1. Baktur R, Patel H, Kwon S. Effect of exposure conditions on SWCNT-induced inflammatory response in human alveolar epithelial cells. Toxicol In Vitro. 2011; 25(5): 1153-1160.

2. Chin SF, Baughman RH, Dalton AB, Dieckmann GR, Draper RK, Mikoryak C, Musselman IH, Poenitzsch VZ, Xie H, Pantano P. Amphiphilic helical peptide enhances the uptake of singlewalled carbon nanotubes by living cells. Exp Biol Med (Maywood). 2007; 232(9): 1236-1244.

3. Dumortier H, Lacotte S, Pastorin G, Marega R, Wu W, Bonifazi D, Briand JP, Prato M, Muller S, Bianco A. Functionalized carbon nanotubes are non-cytotoxic and preserve the functionality of primary immune cells. Nano Lett. 2006; 6(7): 15221528.

4. Helland A, Wick P, Koehler A, Schmid K, Som C. Reviewing the environmental and human health knowledge base of carbon nanotubes. Environ Health Perspect. 2007; 115(8): 1125-1131.

5. Lam CW, James JT, McCluskey R, Arepalli S, Hunter RL. A review of carbon nanotube toxicity and assessment of potential occupational and environmental health risks. Crit Rev Toxicol. 2006; 36(3): 189-217.

6. Yang K, Wang X, Zhu L, Xing B. Competitive sorption of pyrene, phenanthrene, and naphthalene on multiwalled carbon nanotubes. Environ Sci Technol. 2006; 40(18): 5804-5810.

7. Chou CC, Hsiao HY, Hong QS, Chen $\mathrm{CH}$, Peng YW, Chen HW, Yang PC. Single-walled carbon nanotubes can induce pulmonary injury in mouse model. Nano Lett. 2008; 8(2): 437-445.

8. Shvedova AA, Kisin ER, Mercer R, Murray AR, Johnson VJ, Potapovich AI, Tyurina YY, Gorelik $\mathrm{O}$, Arepalli S, Schwegler-Berry D, et al. Unusual inflammatory and fibrogenic pulmonary responses to single-walled carbon nanotubes in mice. $A m J$ Physiol Lung Cell Mol Physiol. 2005; 289(5): L698-708.

9. Warheit DB, Laurence BR, Reed KL, Roach DH, Reynolds GA, Webb TR. Comparative pulmonary toxicity assessment of single-wall carbon nanotubes in rats. Toxicol Sci. 2004; 77(1): 117-125.

10. Muller J, Huaux F, Moreau N, Misson P, Heilier JF, Delos M, Arras M, Fonseca A, Nagy JB, Lison D. Respiratory toxicity of multi-wall carbon nanotubes. Toxicol Appl Pharmacol. 2005; 207(3): 221231.

11. Mitchell LA, Gao J, Wal RV, Gigliotti A, Burchiel SW, McDonald JD. Pulmonary and systemic immune response to inhaled multiwalled carbon nanotubes. Toxicol Sci. 2007; 100(1): 203-214.

12. Lam CW, James JT, McCluskey R, Hunter RL. Pulmonary toxicity of single-wall carbon nanotubes in mice 7 and 90 days after intratracheal instillation. Toxicol Sci. 2004; 77(1): 126-134.

13. Li Z, Hulderman T, Salmen R, Chapman R, Leonard SS, Young SH, Shvedova A, Luster MI, Simeonova PP. Cardiovascular effects of pulmonary exposure to single-wall carbon nanotubes. Environ Health Perspect. 2007; 115(3): 377-382.

14. Donaldson K, Aitken R, Tran L, Stone V, Duffin R, Forrest G, Alexander A. Carbon nanotubes: a review of their properties in relation to pulmonary toxicology and workplace safety. Toxicol Sci. 2006; 92(1): 5-22.

15. Adachi Y, Mio T, Takigawa K, Striz I, Romberger DJ, Spurzem JR, Rennard SI. Fibronectin production by cultured human lung fibroblasts in threedimensional collagen gel culture. In Vitro Cell Dev Biol Anim. 1998; 34(3): 203-210.

16. Fredriksson K, Lundahl J, Fernvik E, Liu XD, Rennard SI, Skold CM. Red blood cells stimulate fibroblast-mediated contraction of three dimensional collagen gels in co-culture. Inflamm Res. 2002; 51(5): 245-251.

17. Infeld MD, Brennan JA, Davis PB. Human tracheobronchial epithelial cells direct migration of lung fibroblasts in three-dimensional collagen gels. $\mathrm{Am}$ J Physiol. 1992; 262(5 Pt 1): L535-541.

18. Agarwal A, Coleno ML, Wallace VP, Wu WY, Sun CH, Tromberg BJ, George SC. Two-photon laser scanning microscopy of epithelial cell-modulated collagen density in engineered human lung tissue. Tissue Eng. 2001; 7(2): 191-202.

19. Mio T, Liu XD, Adachi Y, Striz I, Skold CM, Romberger DJ, Spurzem JR, Illig MG, Ertl R, Rennard SI. Human bronchial epithelial cells modulate collagen gel contraction by fibroblasts. $\mathrm{Am} \mathrm{J}$ Physiol. 1998; 274(1 Pt 1): L119-126.

20. Umino T, Wang H, Zhu Y, Liu X, Manouilova LS, Spurzem JR, Patricia Leuschen M, Rennard SI. Modification of type I collagenous gels by alveolar epithelial cells. Am J Respir Cell Mol Biol. 2000; 22(6): 702-707.

21. Zhang S, Smartt H, Holgate ST, Roche WR. Growth factors secreted by bronchial epithelial cells control myofibroblast proliferation: an in vitro co-culture model of airway remodeling in asthma. Lab Invest. 1999; 79(4): 395-405.

22. Morishima Y, Nomura A, Uchida Y, Noguchi Y, Sakamoto T, Ishii Y, Goto Y, Masuyama K, Zhang MJ, Hirano $\mathrm{K}$, et al. Triggering the induction of 
myofibroblast and fibrogenesis by airway epithelial shedding. Am J Respir Cell Mol Biol. 2001; 24(1): 1-11.

23. Swartz MA, Tschumperlin DJ, Kamm RD, Drazen JM. Mechanical stress is communicated between different cell types to elicit matrix remodeling. Proc Natl Acad Sci USA 2001; 98(11): 6180-6185.

24. Rejman J, Di Gioia S, Bragonzi A, Conese M. Pseudomonas aeruginosa infection destroys the barrier function of lung epithelium and enhances polyplex-mediated transfection. Hum Gene Ther. 2007; 18(7): 642-652.

25. Chambers E, Mitragotri S. Long circulating nanoparticles via adhesion on red blood cells: mechanism and extended circulation. Exp Biol Med (Maywood). 2007; 232(7): 958-966.

26. Patel H, Eo S, Kwon S. Effects of diesel particulate matters on inflammatory responses in static and dynamic culture of human alveolar epithelial cells. Toxicol Lett. 2011; 200(1-2): 124-131.

27. Huh D, Matthews BD, Mammoto A, MontoyaZavala M, Hsin HY, Ingber DE. Reconstituting organ-level lung functions on a chip. Science. 2010; 328(5986): 1662-1668.

28. Shvedova AA, Kisin E, Murray AR, Johnson VJ, Gorelik O, Arepalli S, Hubbs AF, Mercer RR, Keohavong $\mathrm{P}$, Sussman $\mathrm{N}$, et al. Inhalation vs. aspiration of single-walled carbon nanotubes in C57BL/6 mice: inflammation, fibrosis, oxidative stress, and mutagenesis. Am J Physiol Lung Cell Mol Physiol. 2008; 295(4): L552-565.

29. Shinohara N, Nakazato T, Tamura M, Endoh S,
Fukui H, Morimoto Y, Myojo T, Shimada M, Yamamoto $\mathrm{K}$, Tao $\mathrm{H}$, et al. Clearance kinetics of fullerene $\mathrm{C}$ nanoparticles from rat lungs after intratracheal $\mathrm{C}$ instillation and inhalation $\mathrm{C}$ exposure. Toxicol Sci. 2010; 118(2): 564-573.

30. Mercer RR, Hubbs AF, Scabilloni JF, Wang L, Battelli LA, Schwegler-Berry D, Castranova V, Porter DW. Distribution and persistence of pleural penetrations by multi-walled carbon nanotubes. Part Fibre Toxicol. 2010; 7: 28.

31. Pauluhn J. Poorly soluble particulates: searching for a unifying denominator of nanoparticles and fine particles for DNEL estimation. Toxicology. 2011; 279(1-3): 176-188.

32. Tschumperlin DJ, Margulies SS. Equibiaxial deformation-induced injury of alveolar epithelial cells in vitro. Am J Physiol. 1998; 275(6 Pt 1): L11731183.

33. Patel H, Kwon S. Interplay between cytokineinduced and cyclic equibiaxial deformation-induced nitric oxide production and metalloproteases expression in human alveolar epithelial cells. Cellular and Molecular Bioengineering. 2009; 2(4): 615624.

34. Schulte PA. The use of biomarkers in surveillance, medical screening, and intervention. Mutat Res. 2005; 592(1-2): 155-163.

35. Stocker E, Purser F, Kwon S, Park YB, Lee JS. Alternative estimation of human exposure of single-walled carbon nanotubes using three-dimensional tissue-engineered human lung. Int $J$ Toxicol. 2008; 27(6): 441-448. 